\title{
Mathematical models for farm tractor rollover prediction
}

\section{Giorgio Previati, Massimiliano Gobbi and Giampiero Mastinu*}

Department of Mechanical Engineering, Politecnico di Milano, via G. La Masa 1, 20158 Milan, Italy

E-mail: giorgio.previati@polimi.it

E-mail: massimiliano.gobbi@polimi.it

E-mail: mastinu@mecc.polimi.it

${ }^{*}$ Corresponding author

\begin{abstract}
This paper deals with the estimation of the rollover limit of a farm tractor. The rollover phenomenon is investigated by considering the static stability of the farm tractor on a sloped surface. Three mathematical models are derived to understand the basic features of the rollover mechanism. The models are able to predict the (static) rollover limit for any orientation of the farm tractor with respect to the slope. The effects of tyre stiffness (vertical and lateral) and nonsymmetric implement positioning are analysed. The classical architecture of the farm tractor equipped with a pivoting front axle is compared with the adoption of a passively suspended front axle. In case of a front axle suspension, the rollover limit of the vehicle can be improved, especially when employing non-symmetric implements.
\end{abstract}

Keywords: roll-over prediction; farm tractor modelling; static stability.

Reference to this paper should be made as follows: Previati, G. Gobbi, M. and Mastinu, G. (2014) 'Mathematical models for farm tractor rollover prediction', Int. J. Vehicle Design, Vol. 64, Nos. 2/3/4, pp.280-303.

Biographical notes: Giorgio Previatihas got his MSc in Mechanical Engineering in 2002 from Politecnico di Milano, where he also completed his PhD studies in 2006. Afterwards, he was employed in the R\&D facility of a leading farm tractor manufacturer. Since December 2008, he is employed as a Full-time Researcher at the Mechanical Engineering Department of the Politecnico di Milano. His main research fields are related to machine design with particular reference to ground vehicles (modelling and design) and material modelling. The experimental activity is mainlyfocused on mass properties identification, contact force measurement and $\mathrm{NVH}$ evaluation.

Massimiliano Gobbi obtained his MSc in Mechanical Engineering (1994) and $\mathrm{PhD}$ in Applied Mechanics (1998) from Politecnico di Milano, Italy. He is an Associate Professor at the Mechanical Engineering Department, Politecnico di Milano. He has published more than 90 technical papers. His scientific work has been mainly carried out in the field of advanced design methods (optimal design, multi-objective optimisation, etc.) and experimental mechanics. Many applications refer to ground vehicles (road/rail).

Copyright (C) 2014 Inderscience Enterprises Ltd. 


\begin{abstract}
Giampiero Mastinu is a Full Professor of Vehicle System Engineering at the Politecnico di Milano. He has published more than 100 papers in international reviews or symposia, on topics including tyres and wheels, differentials, suspension systems, NVH, active and passive safety, ride comfort, measurement of inertia properties of vehicles, brake design, brake squeal, farm tractor modelling, railway vehicle architecture, wheelset design and optimisation of complex systems. He is one of the founders of the Laboratory for the Safety of Transport (LaST) of the Politecnico di Milano.
\end{abstract}

\title{
1 Introduction
}

Farm tractors are employed for many different operations. Rollovers are typically considered to occur more frequently on sloping terrain, although statistics show that rollovers do occur also on flat ground. Farm tractor rollovers are the major cause of death in farm operations (Abubakar et al., 2010; Bunn et al., 2008). Actually, many researches point out that the farm tractor rollover is one of the most frequent accidents in farming (Ertherton et al., 1991). Rollovers are a result of interactions between the operator, the farm tractor and the environment. The consequences of these accidents in terms of human life and injuries have been greatly reduced by the adoption of rollover protective structures (ROPS) (Day et al., 2004; Loringer and Myers, 2008; Myers, 2000; Myers et al., 2009; Reynolds and Groves, 2000 ) that became mandatory in most countries (Springfeldt, 1996). International standards have been issued on the topic (EC Directive, 2003, 2006; SAE International Standard J1194, 2009). Some studies are related to the design and improvement of such structures (Mangado et al., 2007; Silleli et al., 2007; Silleli et al., 2008). Despite the huge amount of attention and activities on the topic, the rollover phenomenon of farm tractors still deserves to be investigated and understood. The rollover limit can be experimentally estimated (Guzzomi et al., 2009). Tyres have an important effect on the rollover limit of the farm tractor (Febo and Pessina, 2001). Mathematical models can be derived for modelling the rollover of vehicles (Hac et al., 2004), Gillespie (1992) has reported an ultimate contribution on road vehicle rollover in his well known book. Farm tractor rollover has been studied first by Gibson et al. (1971) by developing a three contact model able to predict the stability limit with a good agreement with experimental results. More recently, the dynamic behaviour of the farm tractor when running over a slope has been considered by Mashadi and Nasrolahi (2009) and (Yisa et al., 1998). These models are quite complex and the equations of motion of the vehicle are integrated in the time domain.

In the present paper, the rollover phenomenon is investigated by considering the static stability of the farm tractor on a sloped surface. Even if dynamic conditions usually degrade the stability performances of the farm tractor with respect to static stability, the analysis of static stability provides the basic reference value from which dynamic limits can be estimated (Hunter, 1993).

Three static models of a farm tractor over a sloped surface are considered. The resulting models are rather simple and the effect of the most important parameters of the farm tractor on rollover behaviour can be analysed. The first model describes a standard farm tractor with pivoting front axle and rigid tyres. In the second model the deformation of the tyres is taken into account. By comparing these two models, the effect of tyre deformation is highlighted. 
Finally, the third model accounts for a passively suspended front axle. Since the roll over is mostly dangerous for narrow track tractors, the described models are applied to a small tractor for vineyard and orchard application.

\section{Rollover models}

Three different models for simulating the rollover of a farm tractor mathematically are derived. The first model refers to a standard farm tractor with pivoting front axle and rigid tyres (model A, Section 3). In the second model, deformable tyres are introduced (model B, Section 4). Finally, the third model considers a farm tractor fitted with a suspended front axle (model C, Section 5).

For all of the considered models, the rollover is evaluated by considering the farm tractor resting on a sloped plane. Two different limit situations are considered. At first, the angle for which one wheel of the farm tractor is lifted is computed. In this situation, the farm tractor is in equilibrium with just three contact points with the ground. The stability of such equilibrium will be discussed. Then, the second limit situation refers to the lifting of a second wheel. In this case, an unstable equilibrium condition is found for the farm tractor. The two slope angles corresponding to the lifting of either one or two wheels are computed for all of the possible orientations of the farm tractor with respect to the slope. In Figure 1 the two angles relevant for describing tractor rollover are shown. The attitude of the farm tractor with respect to the slope is defined by angle, $\sigma=0$ when the front of the vehicle is in the direction of the slope. The inclination of the slope is defined by angle $\beta$.

Figure 1 Angles defining respectively the attitude of the farm tractor with respect to the slope $(\sigma)$ and the inclination of the slope $(\beta), \pi$ is the reference plane on which the farm tractor rests
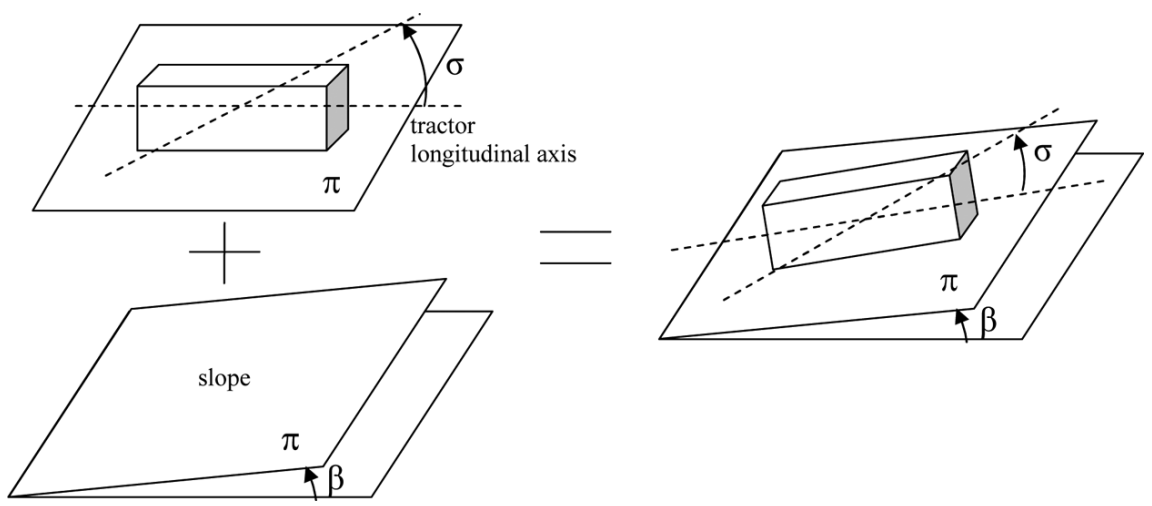

In Figure 2 the mechanical model of a farm tractor is reported. All of the three models presented in the paper consider the same geometrical description of the farm tractor. The height of the roll centre of the front axle $\left(h_{f}\right)$ corresponds to the centre of the cylindrical joint of the axle itself. For the farm tractor with suspended front axle, the roll centre is computed by considering the geometry of the suspension. The height of the roll centre of the rear axle $\left(h_{r}\right)$ is due to the deformation of the rear tyres, it is estimated at $20 \mathrm{~mm}$ for models B and C (Dixon, 1996) and at null for model A (rigid tyre model). The height of the roll centre at the centre of gravity of the farm tractor can be computed as 


$$
h_{0}=\frac{\left(h_{r}-h_{f}\right)}{p} a+h_{f}
$$

The equations are derived in a reference frame attached to the plane $\pi$ (Figure 1) with origin in the middle of the farm tractor rear axle, at ground level. The $x$ axis is parallel to the longitudinal axis of the vehicle, the $y$ axis is oriented towards the lateral direction of the vehicle and the $z$ axis is orthogonal to the plane $\pi$. The forces and the gravity acceleration are respectively projected in the body fixed reference frame, as shown in Figure 3.

Figure 2 Farm tractor geometry

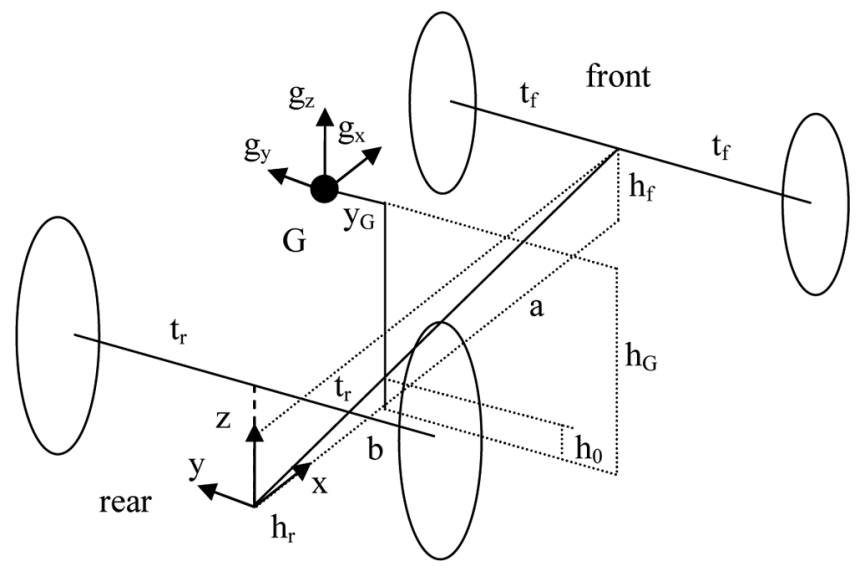

Figure 3 Projection of the contact force acting on the $i$-th tyre in the local reference frame

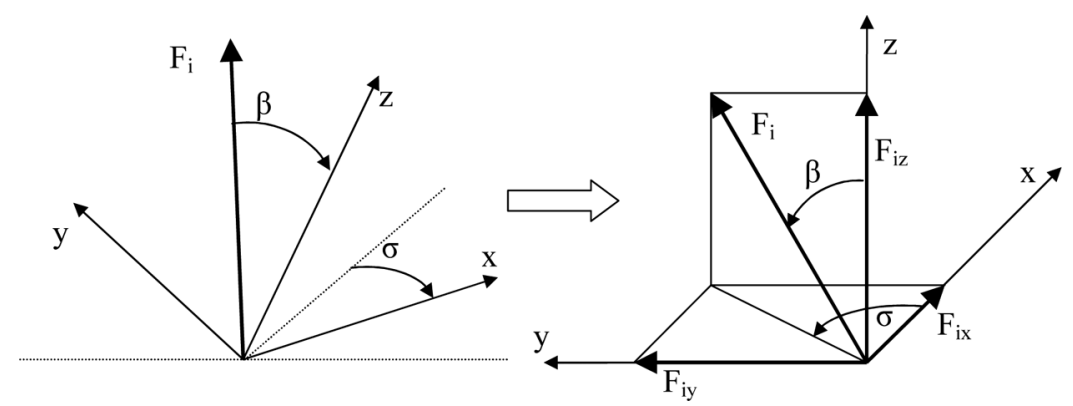

The contact forces are acting in the vertical direction, i.e., each tyre is modelled as a simple support. The components of the contact forces in the body fixed reference system are

$$
\begin{aligned}
& F_{i z}=F_{\underline{i}} \cos (\beta) \\
& F_{i x}=F_{i} \sin (\beta) \cos (\sigma)=F_{i z} \tan (\beta) \cos (\sigma) \\
& F_{i y}=F_{i} \sin (\beta) \cos (\sigma)=F_{i z} \tan (\beta) \sin (\sigma) .
\end{aligned}
$$


The projection of the gravity vector along the respective $x, y, z$ directions is

$$
\left[\begin{array}{l}
g_{x} \\
g_{y} \\
g_{z}
\end{array}\right]=g \cdot\left[\begin{array}{c}
\cos (\beta) \\
\sin (\beta) \cos (\sigma) \\
\sin (\beta) \sin (\sigma)
\end{array}\right], \quad g=-9.81 \frac{m}{s^{2}} .
$$

\section{Model A: rigid model of a farm tractor with pivoting front axle}

This model refers to a standard farm tractor with pivoting front axle. The tyres are considered rigid, i.e., the vertical and lateral deflection of the tyres is neglected.

The interaction between tyre and ground is modelled as a single contact point. The definition of the contact point location in the lateral direction is a subtle issue. In fact, it influences the actual track of the vehicle, which is an important parameter in computing the rollover limit. In this paper, the lateral location of the contact point is estimated as follows. Figure 4 shows the contact patch for a car tyre (225/55R17) in case of vanishing camber angle (Figure 4 left) and in case of a camber angle of $4^{\circ}$ (Figure 4 right), vertical load $4000 \mathrm{~N}$. Such a case has been introduced to refer to an almost cylindrical wheel. It can be observed that the contact patch changes its shape from almost rectangular to almost triangular. In such a situation, it can be stated that the centre of pressure changes its location from the centre of the tyre toward the base of the triangle. In Figure 5 left, the contact patch measured on a farm tractor tyre (300/79R20) with a camber angle of $4^{\circ}$ is shown. In this case, due to the presence of the lungs, the shape of the contact patch cannot be well defined. However, by comparing the contact area at $4^{\circ}$ of camber with the contact area at $0^{\circ}$ of camber (Figure 5 right), it appears that the centre of the area is located closer to the most loaded side of the contact patch while increasing the camber angle. From these observations, it is reasonable, when approaching the rollover conditions, to consider the lateral location of the contact point not in the centre of the tyre but moved towards the most loaded part of the contact patch. In this paper, the displacement from the centre of the patch, is estimated at $1 / 6$ of the width of the tyre. Thus the lateral location of the contact point is estimated at $1 / 3$ of the width of the tyre in the downhill direction (see Figure 6).

Figure 4 Contact area of a car tyre, 225/55R17, load $4000 \mathrm{~N}$ Left: camber $0^{\circ}$ Right: camber $4^{\circ}$
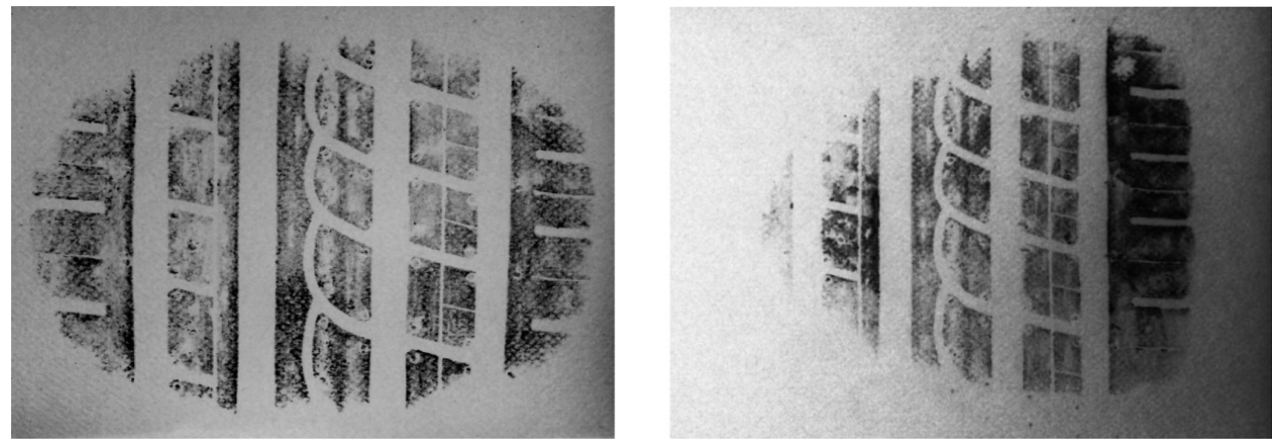
Figure 5 Contact area of a tractor tyre, 300/70R20, load $6500 \mathrm{~N}$ Left: camber $4^{\circ}$ Right: comparison between a camber of $4^{\circ}$ (grey) and a camber of $0^{\circ}$ (black)
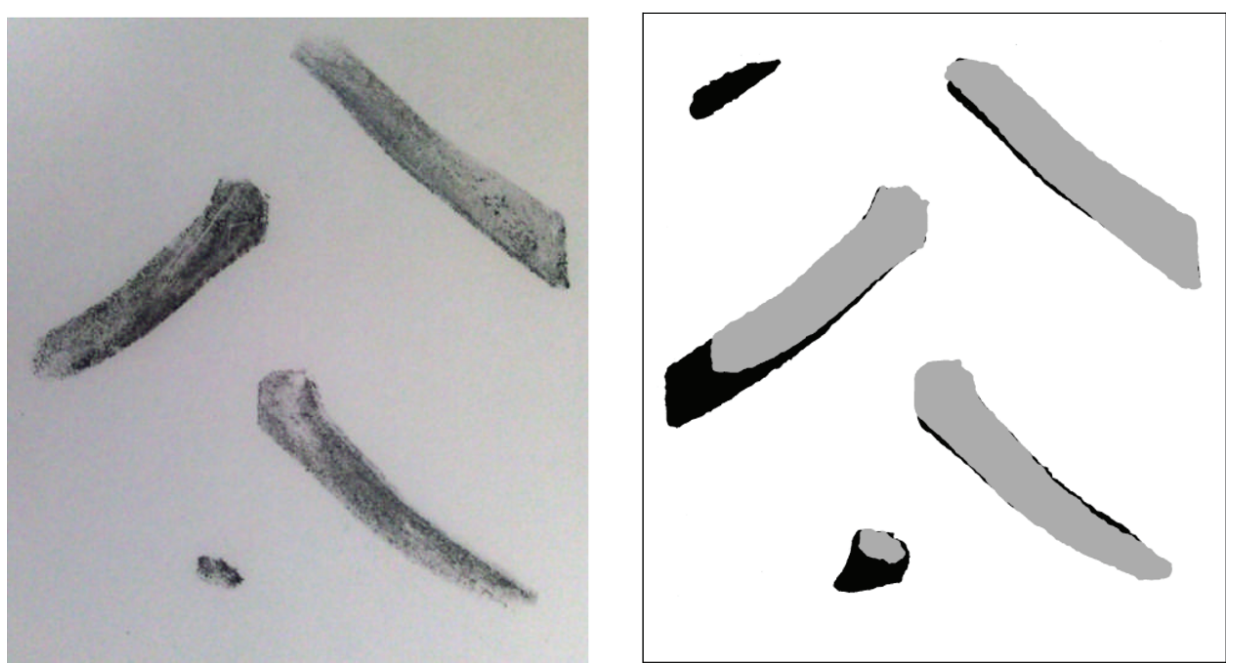

Figure 6 Location of the contact point at $1 / 3$ of the width of the cambered tyre from its outer side

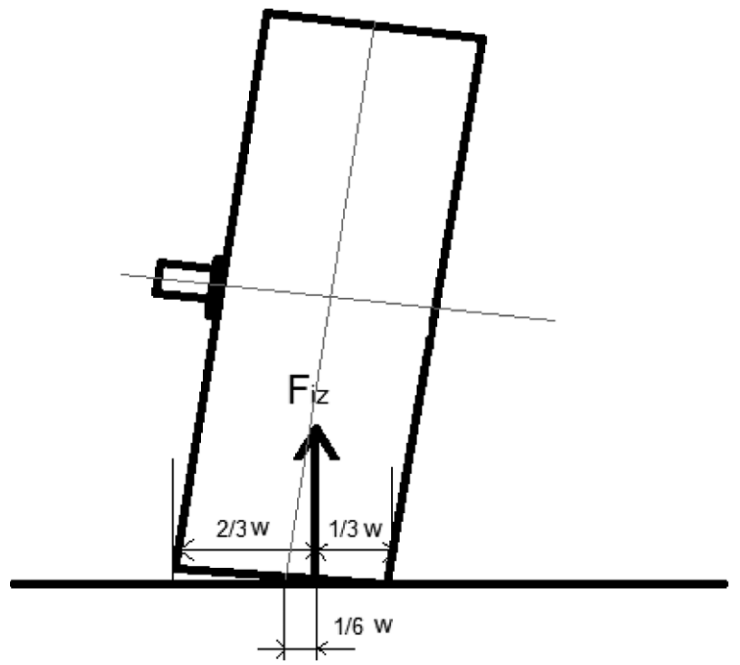

The farm tractor is composed of two rigid bodies, namely the body of the farm tractor (including the rear axle) and the pivoting front axle. The two rigid bodies are connected by a cylindrical joint with axis coincident with the longitudinal axis of the farm tractor, the pivot is located in the centre of the front axle.

\subsection{Lifting of the first wheel}

Figure 7 shows the forces acting on the farm tractor and projected in the body fixed reference frame when four wheels are in contact with the ground. 
Figure 7 Forces acting on the farm tractor at still condition

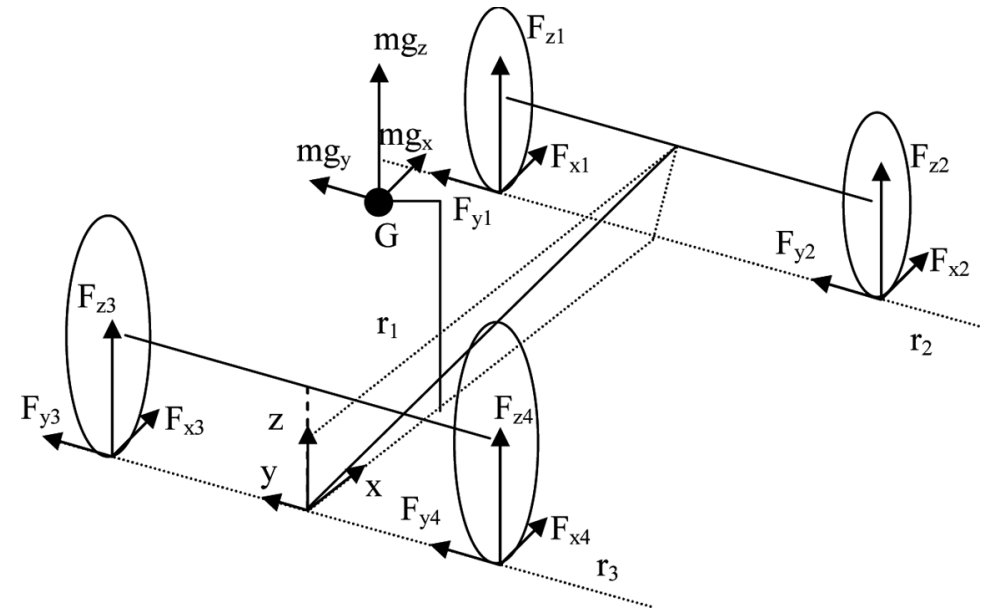

Referring to the convention of Figure 4, the reaction forces acting on the tyres of the farm tractor can be computed by the following equations.

Moment equilibrium around the axis $r_{3}$

$$
F_{z l} p+F_{z 2} p-m g_{x} h_{g}+m g_{z} b=0 .
$$

Moment equilibrium around the axis $r_{1}$ of the front axle

$$
\begin{aligned}
& F_{z 1} t_{f l}+F_{y 1} h_{f}-F_{z 2} t_{f r}+F_{y 2} h_{f}=0 \\
& F_{z 1}\left(t_{f l}+\tan (\beta) \sin (\sigma) h_{f}\right)+F_{z 2}\left(-t_{f r}+\tan (\beta) \sin (\sigma) h_{f}\right)=0
\end{aligned}
$$

where $t_{f t}=t_{f}-w_{f} \cdot \operatorname{sign}(\sin (\sigma)) / 6$ and $t_{f i}=t_{f}+w_{f} \cdot \operatorname{sign}(\sin (\sigma)) / 6$. The sign of the sine of $\sigma$ is computed to identify the uphill direction, the ' $1 / 6$ ' coefficient is used to correctly apply the resultant force in the contact patch.

Moment equilibrium around the axis $r_{2}$

$$
F_{z 3} p+F_{z 4} p+m g_{x} h_{G}+m g_{z} a=0 .
$$

Moment equilibrium around the axis $r_{1}$ of body and rear axle

$$
\begin{aligned}
& F_{z 3} t_{r l}+F_{y 3} h_{f}-F_{z 4} t_{r r}+F_{y 4} h_{f}-m g_{y} h_{G}+m g_{z} y_{G}=0 \\
& F_{z 3}\left(t_{r l}+\tan (\beta) \sin (\sigma) h_{f}\right)+F_{z 4}\left(-t_{r r}+\tan (\beta) \sin (\sigma) h_{f}\right)-m g_{y} h_{G}+m g_{z} y_{G}=0
\end{aligned}
$$

where $t_{r l}=t_{r}-w_{r} \cdot \operatorname{sign}(\sin (\sigma)) / 6$ and $t_{r r}=t_{r}+w_{r} \cdot \operatorname{sign}(\sin (\sigma)) / 6$.

From equations (6) and (7), $F_{z 1}$ and $F_{z 2}$ can be computed and from equations (8) and (9), $F_{z 3}$ and $F_{z 4}$. The limit angle $\beta_{1}$ for which at least one vertical force is vanishing can be computed by applying a Newton method. The value of $\beta_{1}$ is computed for each value of $\sigma$.

\subsection{Lifting of the second wheel}

When one of the wheels is lifted, a different model has to be considered for the equilibrium of the farm tractor. In building the model, two important observations have to be taken into account. 
1 From equation (7) it is clear that the two front wheels lose contact with the ground for the same angle $\beta$. Thus, the equilibrium of the vehicle on three wheels is possible only if one of the rear wheels is the first to lose contact with the ground.

2 When one of the rear wheels is lifted, the body is free to rotate around the pivot point of the front axle. The rotation (roll) of the body is no longer prevented by the moment acting at the rear axle. The actual roll of the body with respect to the front axle depends on the equilibrium of the farm tractor and it can vary from zero to the angle limited by the proper bump stop. Thus, in general, a roll angle is present between the body and the front axis.

Let us consider the case in which the rear left wheel is lifted. In Figure 8, the forces acting on the farm tractor when the rear left wheel is lifted are shown. In Figure 8, the pivoting angle $\rho_{\text {piv }}$ around the cylindrical joint of the front axle is shown. The effect of this angle is a modification of the geometry of the vehicle and thus, following quantities have to be considered.

Figure 8 Farm tractor with the left rear tyre lifted

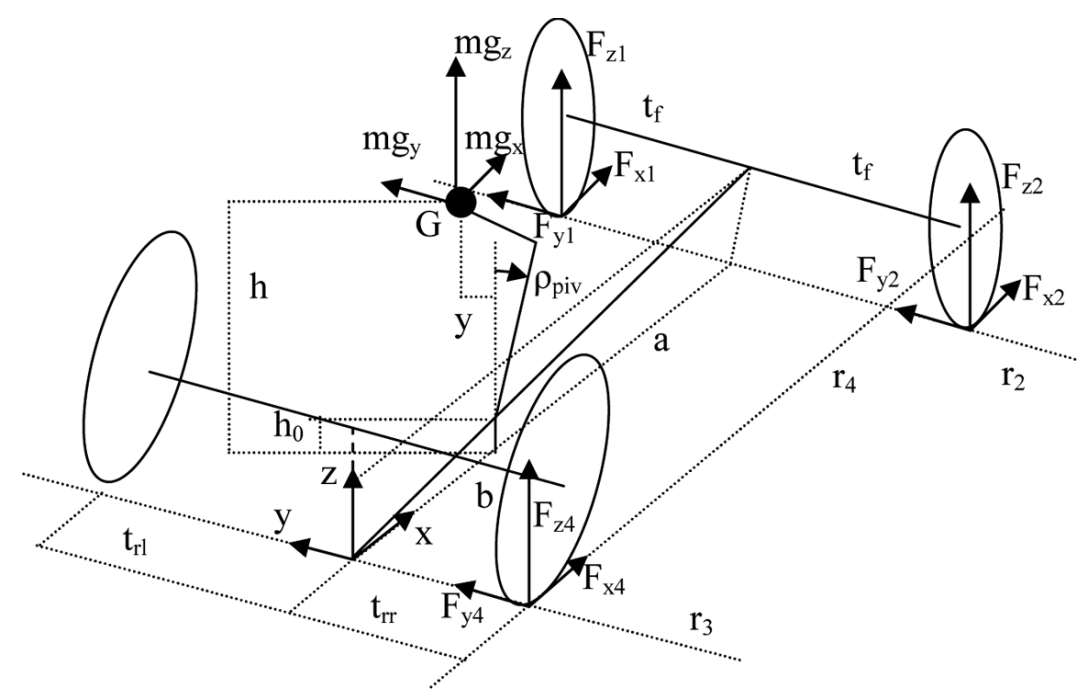

Actual height of the centre of gravity $(h)$

$$
h=\left(h_{G}-h_{0}\right) \cdot \cos \left(\rho_{\text {piv }}\right)+h_{0}+y_{G} \sin \left(\rho_{\text {piv }}\right) .
$$

Actual lateral position of the centre of gravity $(y)$

$$
y=-\left(h_{G}-h_{0}\right) \cdot \sin \left(\rho_{\text {piv }}\right)+y_{G} \cos \left(\rho_{\text {piv }}\right) .
$$

Actual track of the rear left wheel $\left(\mathrm{t}_{r l}\right)$

$$
t_{r l}=t_{r} \cdot \cos \left(\rho_{\text {piv }}\right)+h_{f} \sin \left(\rho_{\text {piv }}\right) .
$$

Actual track of the rear right wheel $\left(t_{r r}\right)$

$$
t_{r r}=t_{r} \cdot \cos \left(\rho_{\text {piv }}\right)-h_{f} \sin \left(\rho_{\text {piv }}\right) .
$$


By considering these quantities, the following equations can be derived. Referring to Figure 4, the moment equilibrium around the axis $r_{3}$ is

$$
F_{z l} p+F_{z 2} p-m g_{x} h+m g_{z} b=0
$$

the moment equilibrium around the axis $r_{2}$ is

$$
F_{z 4} p+m g_{x} h+m g_{z} a=0
$$

the moment equilibrium around the axis $r_{4}$ is

$$
F_{z 1}\left(t_{r r}+t_{f}\right)-F_{z 2}\left(t_{r r}-t_{f}\right)-m g_{y} h+m g_{z}\left(t_{r r}+y\right)=0 .
$$

From equations (14) and (16), $F_{z 1}$ and $F_{z 2}$ can be computed and from equation (15), $F_{z 4}$ is derived. The angle $\beta_{2}$ for which the second wheel is lifted can be numerically computed by applying a Newton method. By varying the angle $\sigma$, the angle $\beta_{2}$ can be estimated for any orientation of the farm tractor with respect to the slope.

A model can be derived for the case in which the rear right wheel is lifted.

\subsection{Results}

Figure 9 shows the rollover limits computed for model A by using the data in Table 1 and a measured value of the stiffness of the tyres. There are three different situations in which the first wheel is lifted. In zone I, there is the simultaneous lifting of the two front wheels. This situation arises for high values of the slope angle $\left(\beta>50^{\circ}\right)$ when the front axle of the farm tractor is higher with respect to the rear axle. For $-30^{\circ}<\sigma<30^{\circ}$ there is no warning for the driver, the two wheels lose contact and the farm tractor upset backwards, i.e., the farm tractors rotates around the axis passing by the contact points of the two rear wheels. The upset due to the rotation around the axis passing by the contact points of the two front wheels occurs for $\beta=180^{\circ}$ only. This is due to the fact that, if $\beta \neq 180^{\circ}$, the body starts immediately rotating around the front axle pivot, preventing the contemporary lifting of the two rear wheels.

Figure 9 Rollover chart for model A. Vehicle data in Table 1. Slope angle $\beta$ and orientation angle $\sigma$ depicted in Figure 1

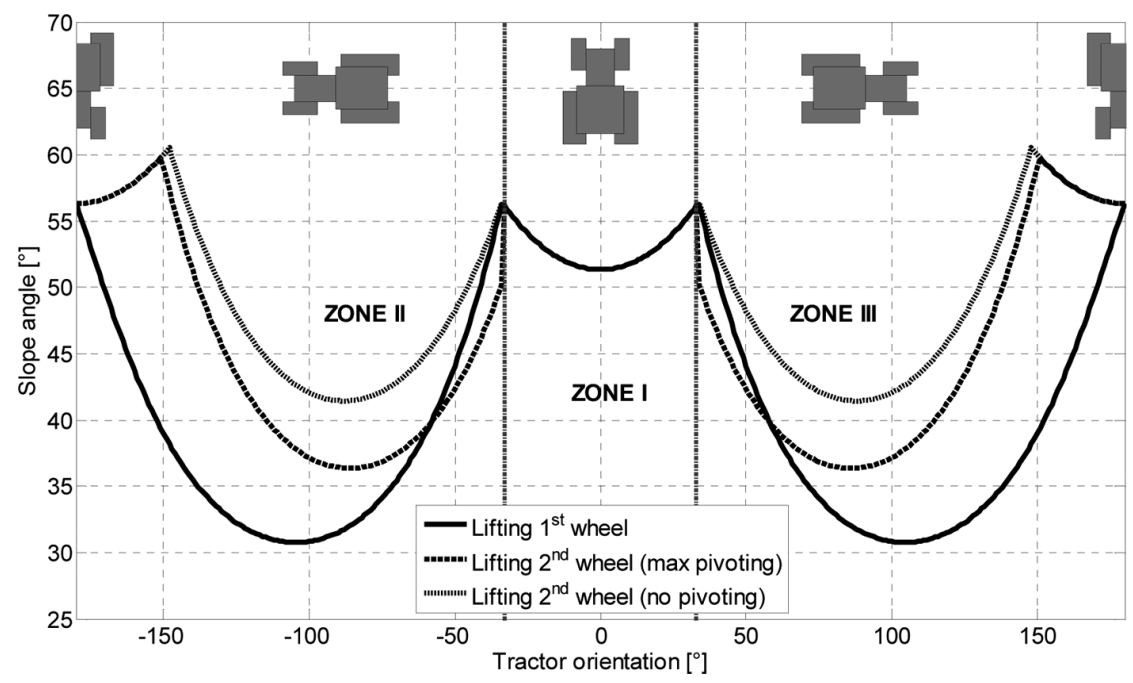


Table 1 Farm tractor data

\begin{tabular}{lc}
\hline Mass $(\mathrm{m})$ & $3000 \mathrm{~kg}$ \\
\hline Wheelbase $(p)$ & $2.2 \mathrm{~m}$ \\
Front track $\left(t_{f}\right)$ & $0.7 \mathrm{~m}$ \\
Rear track $\left(t_{r}\right)$ & $0.6 \mathrm{~m}$ \\
c.g. $x$ coordinate (from rear axle) $(b)$ & $1 \mathrm{~m}$ \\
c.g. $y$ coordinate (from medial axis) $\left(y_{G}\right)$ & $0 \mathrm{~m}$ \\
c.g. $z$ coordinate (from ground) $\left(h_{G}\right)$ & $0.8 \mathrm{~m}$ \\
Maximum pivoting angle & $\pm 8^{\circ}$ \\
Front axle roll centre height $\left(h_{f}\right)$ & $0.45 \mathrm{~m}$ \\
Rear axle roll centre height $\left(h_{r}\right)$ & $0 \mathrm{~m}$ \\
Front tyres width $\left(w_{f}\right)$ & $300 \mathrm{~mm}$ \\
Rear tyres width $\left(w_{r}\right)$ & $420 \mathrm{~mm}$ \\
\hline
\end{tabular}

Referring to zones II and III, the lifting of the second wheel is shown for the two limit situations, one corresponding to the maximum pivot angle allowed by the bump stop and the other corresponding to a null pivot angle.

In zone II and zone III, there is the lifting of the left or the right rear wheel, respectively. When the centre of gravity lies in the midplane of the farm tractor, these two zones are symmetric. The minimum of $\beta_{1}$ is for orientation of $\sigma= \pm 105^{\circ}$ where $\beta_{1}=30.8^{\circ}$. The minimum of $\beta_{2}$ is reached for an orientation angle $\sigma= \pm 88^{\circ}$ for a slope angle $\beta_{2}=41.4^{\circ}$, if the body has no pivoting angle. But, if the body is pivoted, the minimum of $\beta_{1}$ is $36.3^{\circ}$, for an orientation of $\pm 86^{\circ}$. A strange situation occurs for orientations between $30^{\circ}$ and $60^{\circ}$ (and $-30^{\circ}$ and $-60^{\circ}$ ). In this zone, when the body is pivoted, the lifting of the second wheel is computed for lower slope angles with respect to the lifting of the first wheel. This means that the vehicle is quite unstable and if the equilibrium is perturbed the farm tractor rolls over suddenly. In Figure 10 the same information from Figure 9 is reported in a polar representation.

The actual value of the pivoting angle depends on the potential energy of the system. In Figure 11, the variation of the height of the centre of gravity due to the pivoting of the body is reported for

Figure 10 Polar representation of the rollover limit of the farm tractor (model A)

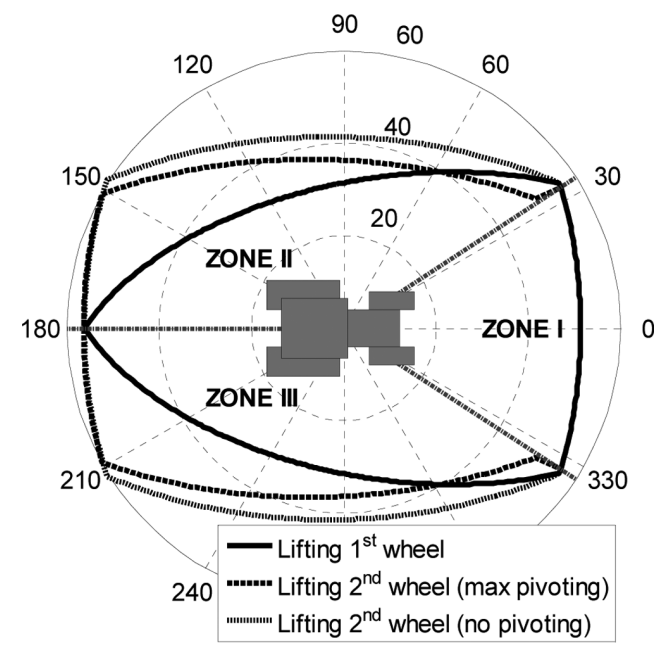


Figure 11 Variation of the height of the centre of gravity due to the pivoting of the body computed for an orientation $\sigma=90^{\circ}$ and for a slope angle $\beta=31.5^{\circ}$ corresponding to the lifting of the first wheel

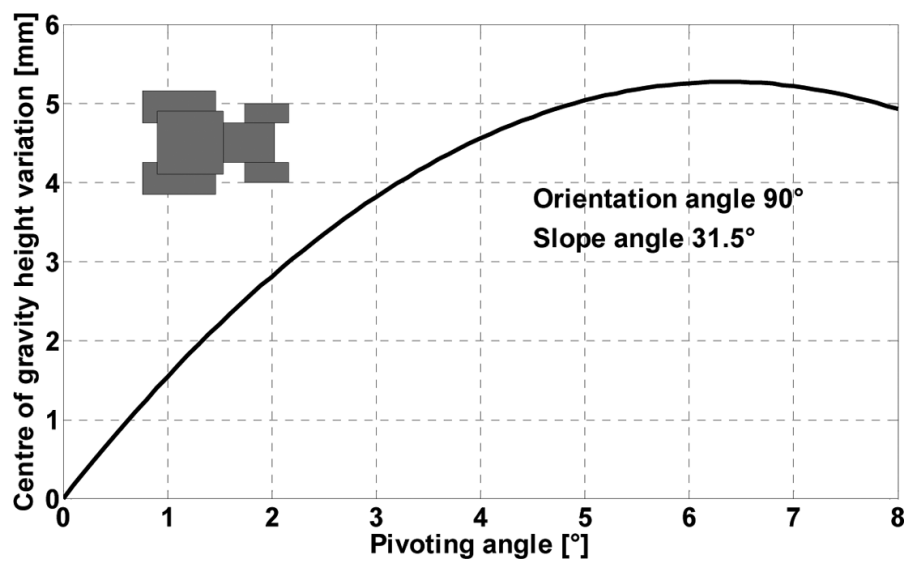

an orientation $\sigma=90^{\circ}$ (Figure 1) and for a slope angle $\beta$ corresponding to the lifting of the first wheel, precisely the rear left wheel, $\beta=31.5^{\circ}$. For small displacements, the rotation of the farm tractor with respect to the ground is around the axis connecting the cylindrical joint (pivot) of the front axle to the centre of the hub of the rear right wheel. In this situation, there is an increase in the height of the centre of gravity. In Figure 11, the vertical displacement of the centre of gravity has been computed for different rotation angles. An increment of $5 \mathrm{~mm}$ in the height of the centre of gravity is required for increasing the pivoting angle from $0^{\circ}$ to $8^{\circ}$. This means that the equilibrium with a pivoting angle of $0^{\circ}$ is stable, but only for small perturbations. This can be very dangerous: actually, the rollover limit is much lower when a pivoting angle is present and relatively small perturbations are sufficient to increase the pivoting angle. For different orientation and slope angles, the shape of the relationship between the pivoting angle and the height of the centre of gravity changes. In Figure 12, the results of model A are compared with

Figure 12 Rollover chart. Comparison between model A and the stability triangle model (Gibson et al., 1971).Vehicle data in Table 1. Slope angle $\beta$ and orientation angle $\sigma$ depicted in Figure 1

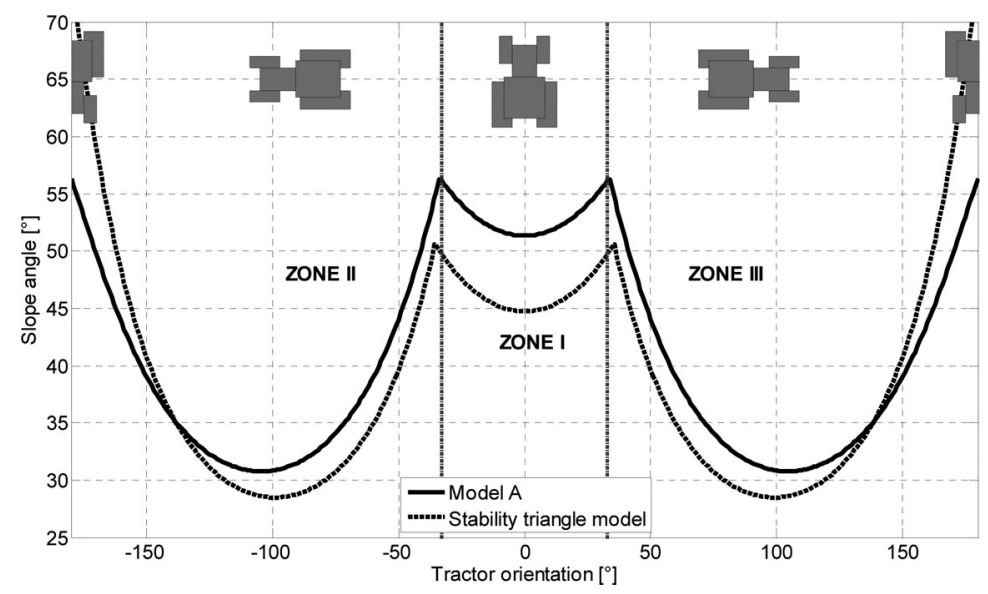


the results of the stability triangle model developed by Gibson et al. (1971). In this model, the tractor is considered to be a rigid body with three supporting points: two are the contact points representing the rear wheels and one is in the location of the cylindrical joint connecting the chassis and the front axle. The stability limit of the vehicle is then computed as the angle that makes the projection of the centre of gravity of the sole chassis (the mass of the front axle is neglected) to lie outside the triangle passing through the three supporting points. Figure 12 shows a good agreement between the two models; in particular, the two models estimate the minimum angle with a difference of less than $2.5^{\circ}\left(\beta=30.8^{\circ}\right.$ for model $\mathrm{A}$ and $\beta=28.5^{\circ}$ for the stability triangle model) and for almost the same attitude of the tractor $\left(\sigma=105^{\circ}\right.$ for model A and $\sigma=100^{\circ}$ for the stability triangle model). The results of the two models show some differences when the tractor is in the direction of the slope (zone I) or in the opposite direction $\left(\sigma\right.$ near $\left.\pm 180^{\circ}\right)$. This is because the stability triangle model does not consider the effect of the front axle, which increases the stability angle when the front of the vehicle is toward the slope and decreases it in the other case.

The stability triangle model is specific for vehicles with a pivoting front axle; model A is conceived so as to be easily modified for the study of farm tractors with suspended front axle (see Section 5).

\section{Model B: model of a tractor with pivoting front axle and deformable tyres}

In this model, the effect of the deformation of the tyres is considered. The tyres can deform vertically and laterally. Due to the vertical deformation of the tyres, the body and the front axle have a roll angle. The roll angles of the body and of the front axle are different, since they are connected through a cylindrical joint that allows a relative roll angle. The lateral deformation of the tyres reduces the actual track of the downhill wheels.

\subsection{Lifting of the first wheel}

Calling $\rho_{f}$ and $\rho_{r}$ the roll angles at the front and rear axle respectively, the following quantities can be computed.

Actual height of the centre of gravity $(h)$

$$
h=\left(h_{G}-h_{0}\right) \cdot \cos \left(\rho_{r}\right)+h_{0}+y_{G} \sin \left(\rho_{r}\right) .
$$

Actual lateral position of the centre of gravity $(y)$

$$
y=-\left(h_{G}-h_{0}\right) \cdot \sin \left(\rho_{r}\right)+y_{G} \cos \left(\rho_{r}\right)
$$

Actual track of the front left wheel $\left(t_{f 1}\right)$

$$
t_{f 1}=t_{f 10} \cdot \cos \left(\rho_{f}\right)+h_{f} \sin \left(\rho_{f}\right)
$$

where $t_{f 0}$ is the front track corrected for the lateral deformation of the tyre and for the location of the contact point

$$
t_{f 10}=t_{f}-\frac{w_{f}}{6} \cdot \operatorname{sign}(\sin (\sigma))+\frac{F_{y 1}}{k_{f L}}
$$

the sign of the sine of $\sigma$ is computed to evaluate the uphill direction. 
Actual track of the front right wheel $\left(t_{f i}\right)$

$$
t_{f r}=t_{f r 0} \cdot \cos \left(\rho_{f}\right)-h_{f} \sin \left(\rho_{f}\right), \quad t_{f r 0}=t_{f}+\frac{w_{f}}{6} \cdot \operatorname{sign}(\sin (\sigma))+\frac{F_{y 2}}{k_{f L}}
$$

Actual vertical distance between the front left wheel and the roll centre of the front axles $\left(h_{f}\right)$

$$
h_{f t}=h_{f} \cos \left(\rho_{f}\right)-t_{f} \sin \left(\rho_{f}\right) .
$$

Actual vertical distance between the front right wheel and the roll centre of the front axles $\left(h_{f r}\right)$

$$
h_{f r}=h_{f} \cos \left(\rho_{f}\right)-t_{f} \sin \left(\rho_{f}\right) .
$$

Actual track of the rear left wheel $\left(t_{r 1}\right)$

$$
t_{r l}=t_{r l 0} \cdot \cos \left(\rho_{r}\right)+h_{r} \sin \left(\rho_{r}\right), \quad t_{r l 0}=t_{r}-\frac{w_{r}}{6} \cdot \operatorname{sign}(\sin (\sigma))+\frac{F_{y 3}}{k_{r L}} .
$$

Actual track of the rear right wheel $\left(t_{r r}\right)$

$$
t_{r r}=t_{r 10} \cdot \cos \left(\rho_{r}\right)-h_{r} \sin \left(\rho_{r}\right), \quad t_{r 10}=t_{r}+\frac{w_{r}}{6} \cdot \operatorname{sign}(\sin (\sigma))+\frac{F_{y 4}}{k_{r L}} .
$$

Actual vertical distance between the rear left wheel and the roll centre of the rear axles $\left(h_{r 1}\right)$

$$
h_{r l}=h_{r} \cos \left(\rho_{r}\right)-t_{r} \sin \left(\rho_{r}\right) .
$$

Actual vertical distance between the rear right wheel and the roll centre of the rear axles $\left(h_{r r}\right)$

$$
h_{r r}=h_{r} \cos \left(\rho_{r}\right)-t_{r} \sin \left(\rho_{r}\right) .
$$

By considering the above defined quantities and referring to Figure 4, equations (8) and (9), the equilibrium equations of the rear axle, can be rewritten as follows.

Moment equilibrium around the axis $r_{2}$

$$
F_{z 3} p+F_{z 4} p+m g_{x} h+m g_{z} a=0 .
$$

Moment equilibrium around the axis $r_{1}$ of body and rear axle

$$
\begin{aligned}
& F_{z 3} t_{r l}+F_{y 3} \cdot\left(h_{f}-h_{r}+h_{r l}\right)-F_{z 4} t_{r r}+F_{y 4} \cdot\left(h_{f}-h_{r}+h_{r r}\right)-m g_{y} h+m g_{z} y=0 \\
& F_{z 3}\left(t_{r}+\tan (\beta) \sin (\sigma)\left(h_{f}-h_{r}+h_{r l}\right)\right)+F_{z 4}\left(-t_{r}+\tan (\beta) \sin (\sigma)\left(h_{f}-h_{r}+h_{r r}\right)\right)-m g_{y} h+m g_{z} y=0
\end{aligned}
$$

where the effects of the roll angles on the height of the roll centres of the front and rear axles have been neglected. Equations (28) and (29) are dependent on $\rho_{r}$, so a third equation has to be derived describing the relationship between the roll angle and the forces along the local $z$ direction.

$$
F_{Z 3}-F_{Z 4}-K_{r} \cdot\left(h_{r l}-h_{r r}\right)=0
$$

where $k_{r}$ is the vertical stiffness of the rear tyres. By solving the system of equations (28), (29) and (30), $F_{z 3}, F_{z 4}$ and $\rho_{r}$ can be computed. As this system is nonlinear with respect to the forces and $\rho_{r}$, a Newton method has been applied for the solution.

Similarly, equations (6) and (7), regarding the equilibrium of the front axle, can be rewritten. 
Moment equilibrium around the axis $r_{3}$

$$
F_{Z 1} p+F_{z 2} p-m g_{x} h+m g_{z} b=0 .
$$

Moment equilibrium around the axis $r_{1}$ of the front axle

$$
\begin{aligned}
& F_{z 1} t_{f l}+F_{y 1} h_{f l}-F_{z 2} t_{f r}+F_{y 2} h_{f r}=0 \\
& F_{z 1}\left(t_{f l}+\tan (\beta) \sin (\sigma) h_{f l}\right)+F_{z 2}\left(-t_{f r}+\tan (\beta) \sin (\sigma) h_{f r}\right)=0 .
\end{aligned}
$$

Equations (31) and (32) are dependent on $\rho_{f}$, so a third equation has to be derived describing the relationship between the roll angle and the forces along the local $z$ direction.

$$
F_{z 1}-F_{z 2}-k_{f} \cdot\left(h_{f t}-h_{f r}\right)=0
$$

where $k_{f}$ is the vertical stiffness of the front tyres. By solving the system of equations (31), (32) and (33), $F_{z 1}, F_{z 2}$ and $\rho_{a}$ can be computed. As this system is nonlinear with respect to the forces and $\rho_{a}$, a Newton method has been used. Equation (31) is also function of $\rho_{r}$. Therefore, the equilibrium of the front axle can be solved after the equilibrium of the rear axle has been computed.

As already done for model $\mathrm{A}$, the limit angle $\beta_{1}$ for which at least one vertical force is null is computed. The value of $\rho_{1}$ is computed for each value of $\sigma$.

\subsection{Lifting of the second wheel}

As in the previous case, by inspecting equation (32) one can notice that the two front wheels lose contact with the ground for the same angle. When one of the rear wheels is lifted, the rotation of the body around the pivot of the front axle is defined by the potential energy of the system. As the most dangerous situation is when the body reaches the bump stop, only this situation is considered and the roll angle of the body is be computed as

$$
\rho_{r}=\rho_{f}+\rho_{\text {piv }}
$$

Let us consider the case in which the rear left wheel is lifted.

By considering equation (34), the actual quantities of the previous section can be recomputed for this new configuration. The equilibrium can be found by combining equations (6), (7) and (8), which are now functions of the contact force and of the roll angle, with equation (14). The resulting system can be solved by a Newton method.

The angle $\beta_{2}$ for which the second wheel is lifted can be computed by a Newton method. By varying the angle $\sigma$, the angle $\beta_{2}$ can be estimated for any orientation of the farm tractor with respect to the slope. A similar model can be derived for the case in which the rear right wheel is lifted.

\subsection{Results}

In Figure 13, the rollover limits computed for a tractor with pivoting front axle by using model $\mathrm{B}$ are reported. The stiffness of the tyres is reported in Table 2. The results of model $\mathrm{B}$ are qualitatively similar to the results of model A. In Figure 14, a comparison of the two models is reported for the lifting of the first wheel (left) and of the second wheel (right). Model B estimates lower values of the slope angle with respect to model A. This is due to the vertical deformation of the tyres, which causes a roll angle in the direction of the slope and to the lateral deformation of the tyres, which reduces the actual track of the downhill wheel (it 
Figure 13 Rollover chart for model B. Data in Tables 1 and 2. Slope angle $\beta$ and orientation angle $\sigma$ depicted in Figure 1

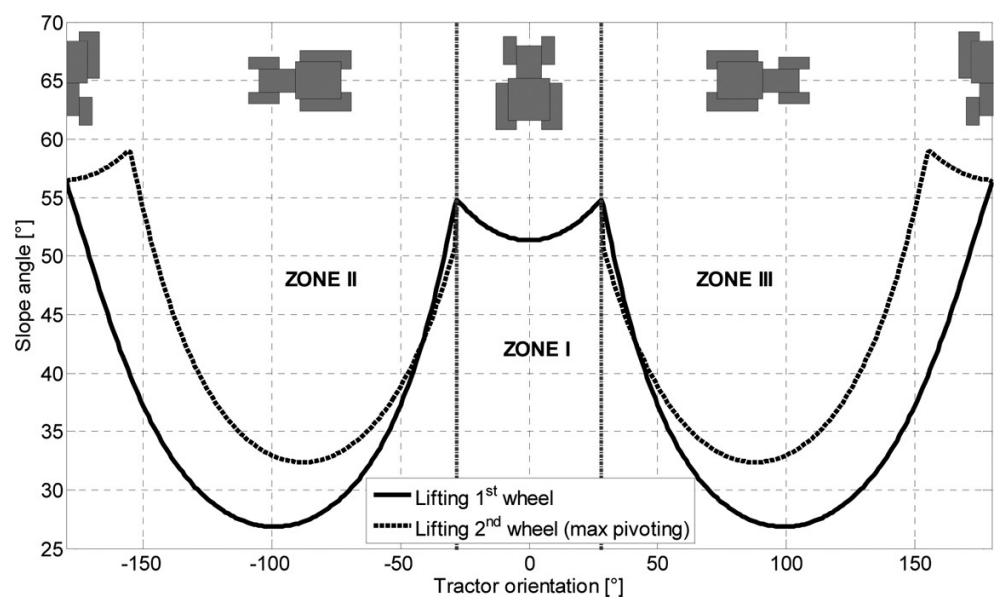

Table 2 Tractor data for model B

\begin{tabular}{ll}
\hline Front tyres vertical stiffness $\left(k_{f}\right)$ & $240000 \mathrm{~N} / \mathrm{m}$ \\
Front tyres lateral stiffness $\left(k_{f L}\right)$ & $160000 \mathrm{~N} / \mathrm{m}$ \\
Rear tyres vertical stiffness $\left(k_{r}\right)$ & $260000 \mathrm{~N} / \mathrm{m}$ \\
Rear tyres lateral stiffness $\left(k_{r L}\right)$ & $170000 \mathrm{~N} / \mathrm{m}$ \\
\hline
\end{tabular}

Figure 14 Comparison between rollover limit computation for model A and for model B. Left: lifting of the first wheel. Right: lifting of the second wheel. Vehicle data in Tables 1 and 2
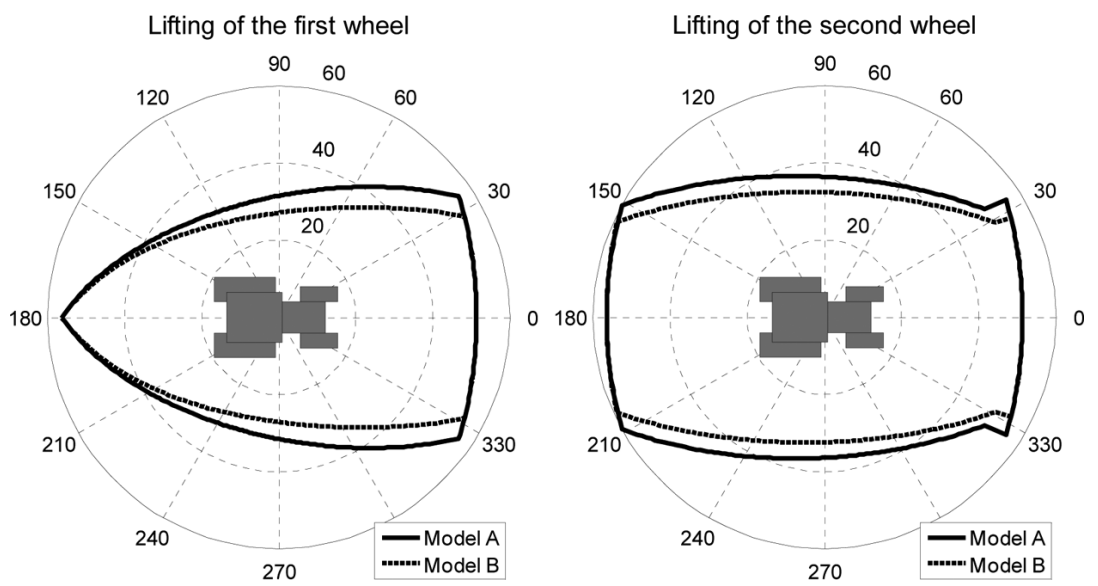

increases the actual track of the uphill wheel, but this has small effect in the computation of the rollover limit). The minimum angle $\beta_{1}$ computed by model $\mathrm{B}$ is $26.8^{\circ}$, while for model $\mathrm{A}$ this angle is $30.8^{\circ}$. Model A overestimates this angle up to $15 \%$. Regarding the lifting of the second wheel, model $\mathrm{B}$ estimates the minimum $\beta_{2}$ to be $32.3^{\circ}$, while in model $\mathrm{A}$ it is $36.2^{\circ}$. 


\section{Model C: model of a tractor with suspended front axle and deformable tyres}

In this section, a model for a farm tractor equipped with a front axle suspension is presented. The considered front axle suspension has a double wishbone scheme and hydro-pneumatic actuators (Bastow, 1993). The scheme of the suspension, the hydro-pneumatic connection and the parameters are reported the Appendix. For defining a rollover model, the suspension is described by means of an interpolating curve giving the roll moment of the suspension as a function of the vertical load acting on the suspension and of the roll angle (see Fig. 15). By this description, the roll stiffness of the suspension is a function of the roll angle, while the roll centre is considered as fixed.

Figure 15 Roll characteristic of the front axle suspension. Roll moment as function of the roll angle and of the vertical force acting on the front axle

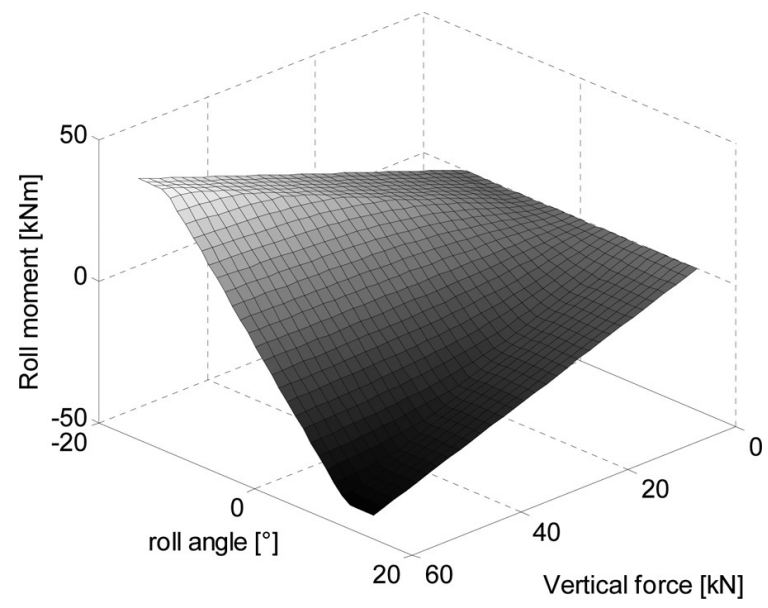

Let us consider how the roll moment is split between the front and rear axle when a suspension is present on the front axle only. The moments acting on the front and on the rear axles can be computed as

$$
\begin{aligned}
& M_{\text {front }}=K_{\text {front }} \rho=\left(\frac{1}{K_{\text {front }, t}}+\frac{1}{K_{\text {front }, s}}\right)^{-1} \rho \\
& M_{\text {rear }}=K_{\text {rear }} \rho=K_{\text {rear }, t} \rho
\end{aligned}
$$

where $K_{\text {front }, t}$ and $K_{\text {front }, s}$ are the roll stiffness due to the tyres and to the suspension at the front axle, while $K_{\text {rear }, t}$ is the stiffness of the rear axle due to the rear tyres. The ratio between the moments on the front and rear axles can be expressed as

$$
\frac{M_{\text {front }}}{M_{\text {rear }}}=\frac{\left(\frac{1}{K_{\text {front }, t}}+\frac{1}{K_{\text {front }, s}}\right)^{-1}}{K_{\text {rear }, t}}=\frac{K_{\text {front }, t}}{K_{\text {rear }, t}} \cdot \frac{K_{\text {front }, s}}{K_{\text {front }, t}+K_{\text {front }, s}} .
$$


As $K_{\text {front }, t}$ and $K_{\text {rear, } t}$ are almost the same, equation (37) shows that to have a comparable rolling moment on the two axes, the front suspension has to be very stiff, with a roll stiffness of the same order of magnitude of the roll stiffness due to the tyres. If such a stiff suspension is employed, the reaction moment of the suspended front axle when the tractor is tilted can be greater than the reaction moment of the pivoting front axle and the stability limit of the tractor can be improved, as shown by the following model.

\subsection{Lifting of the first wheel}

The vehicle model with suspended front axle is illustrated in Figure 16. The front axle is removed and only the forces and the moment acting on the roll centre are considered. The roll centre is computed from the geometry of the suspension and its position is considered constant as the vehicle rolls. Due to the deformation of the rear tyres and to the presence of the front suspension, the body of the vehicle has a roll angle. The geometry description of the vehicle when a roll angle is present is formally equal to the one reported in the previous section.

Figure 16 Scheme of the farm tractor with suspended front axle

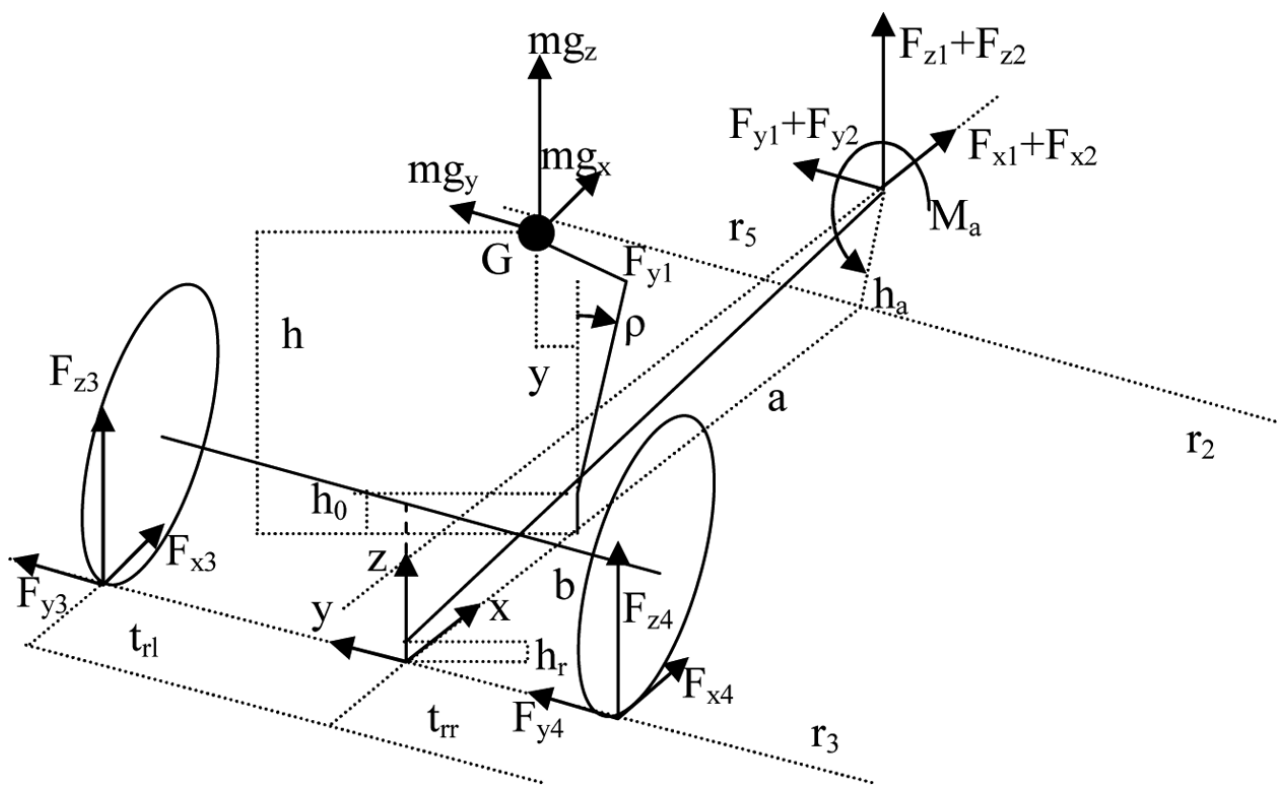

The equilibrium of the vehicle can be computed as follows. The moment equations around $r_{2}$ and $r_{3}$ can be used and are formally identical to equations (28) and (31).

Rotation of the body around the longitudinal axis $r_{5}$ passing through the roll centre of the front axle

$$
\begin{aligned}
& F_{z 3} t_{r l}+F_{y 3} \cdot\left(h_{f}-h_{r}+h_{r l}\right)-F_{z 4} t_{r r}+F_{y 4} \cdot\left(h_{f}-h_{r}+h_{r r}\right)-m g_{y} h+m g_{z} y+M_{a}=0 \\
& F_{z 3}\left(t_{r}+\tan (\beta) \sin (\sigma)\left(h_{f}-h_{r}+h_{r l}\right)\right)+ \\
& F_{z 4}\left(-t_{r}+\tan (\beta) \sin (\sigma)\left(h_{f}-h_{r}+h_{r r}\right)\right)-m g_{y} h+m g_{z} y+M_{a}=0
\end{aligned}
$$


where the effects of the roll angles on the height of the roll centres of the front and rear axles have been neglected.

Equations (28), (31) and (35) are dependent on the roll angle of the vehicle $(\rho)$, so a third equation has to be derived describing the relationship between the roll angle and the rear forces along the local $z$ direction. This equation is formally identical to equation (30).

As done for the previous models (A and $\mathrm{B}$ ), the limit angle $\beta_{1}$ for which at least one vertical force is null is computed by applying a Newton method. The value of $\beta_{1}$ is computed for each value of $\sigma$.

\subsection{Lifting of the second wheel}

Due to the chosen hydro-pneumatic connection of the actuators (see Appendix), the two front wheels lose contact with the ground simultaneously. Thus, the equilibrium of the vehicle on three wheels is possible only if one of the rear wheels is the first to lose contact with the ground. In the presence of a front suspension, the free pivoting of the front axle is no longer possible. The equilibrium of the vehicle on three wheels can be computed from equations (38), (31) and (35) by considering the forces acting on the lifted rear wheel as vanishing.

\subsection{Results}

Figure 17 shows the rollover chart for the farm tractor with suspended front axle. The qualitative behaviour is similar to the case of the farm tractor with pivoting front axle. The comparison between model $\mathrm{C}$ and model B is reported in Figure 18. The farm tractor equipped with a suspended front axle has a rollover limit higher or equal to the limit of the farm tractor with pivoting front axle, both referring to the lifting of the first and second wheel. The minimum angle for the lifting of the first wheel is $26.8^{\circ}$ for model $\mathrm{B}$ and $34^{\circ}$ for

Figure 17 Rollover chart for model C. Data in Tables 1 and 2 and in Appendix. Slope angle $\beta$ and orientation angle depicted in Figure 1

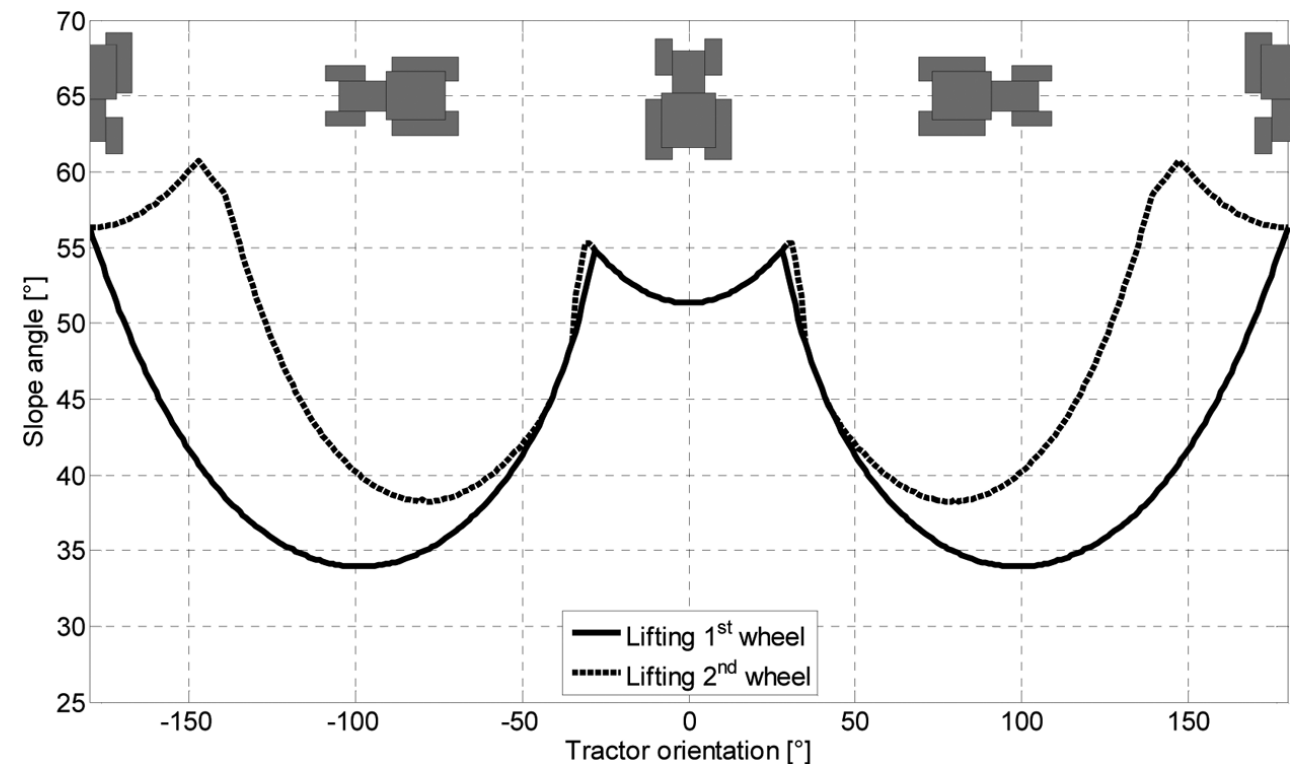


Figure 18 Comparison between rollover limit estimation of model B and of model C. Left: lifting of the first wheel. Right: lifting of the second wheel. Vehicle data in Tables 1 and 2 and in the Appendix
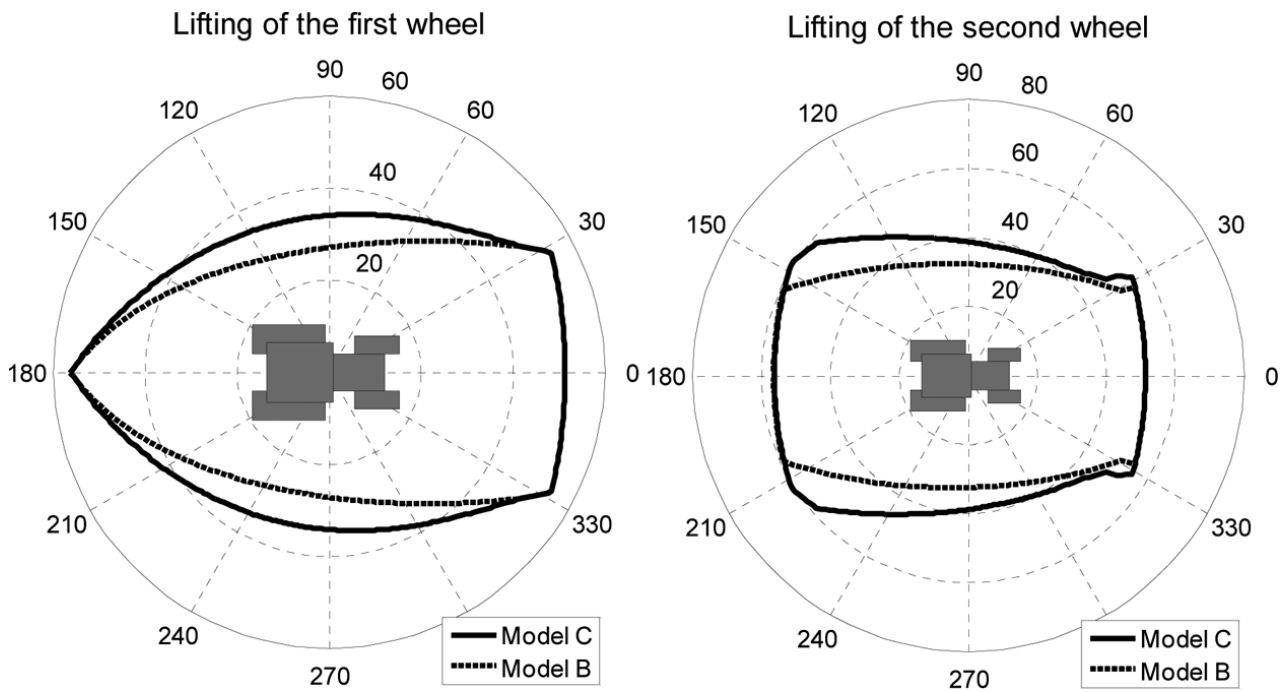

model C. The presence of the front axle suspension improves this minimum angle by $20 \%$. Regarding the lifting of the second wheel, the increment of the minimum roll over angle is $18 \%$ ( $32.3^{\circ}$ for model B and $38.2^{\circ}$ for model C).

In Figure 19 the comparison between the rollover limits for model $\mathrm{B}$ and model $\mathrm{C}$ is reported in the case of a non-symmetric implement being applied to the vehicle (data in

Figure 19 Comparison between rollover limit estimation of model B and model $\mathrm{C}$ when equipped with a non-symmetric implement. Left: lifting of the first wheel. Right: lifting of the second wheel. Vehicle/implement data in Tables 1, 2, 3 and in Appendix

\section{Lifting of the first wheel}

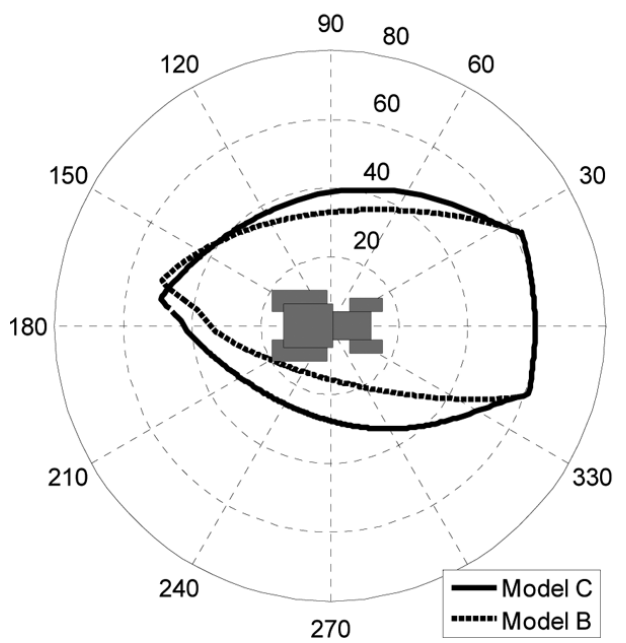

Lifting of the second wheel

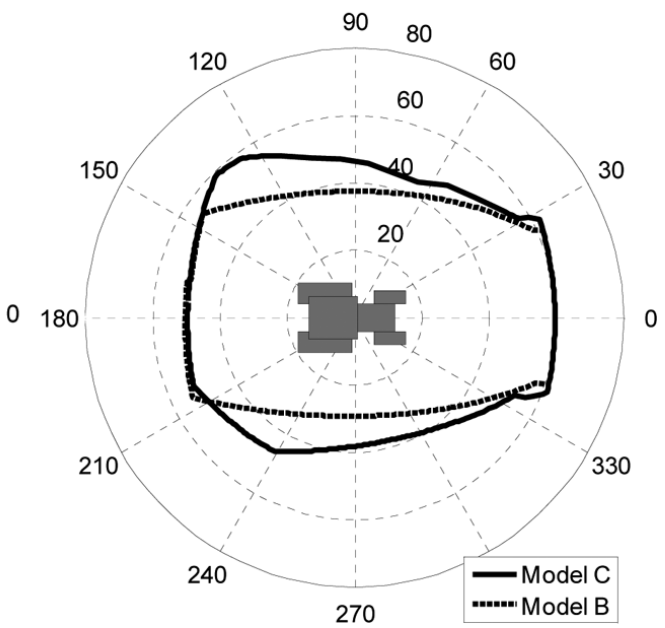


Table 3). The presence of the front axle suspension allows for a much higher safety margin, especially for the lifting of the first wheel (minimum angle of $15^{\circ}$ for model B and $26.1^{\circ}$ for model $\mathrm{C},+73 \%)$. The minimum angle for the lifting of the second wheel is $29.2^{\circ}$ for model $\mathrm{B}$ and $37.7^{\circ}$ for model $\mathrm{C}(+29 \%)$.

Table 3 Non-symmetric implement data

\begin{tabular}{ll}
\hline Mass (m) & $600 \mathrm{~kg}$ \\
c.g. x coordinate (from rear axle) & $2.8 \mathrm{~m}$ \\
c.g. y coordinate (from medial axis) & $0.6 \mathrm{~m}$ \\
c.g. z coordinate (from ground) & $0.6 \mathrm{~m}$ \\
\hline
\end{tabular}

\section{Conclusion}

The problem of the rollover of farm tractors has been analysed. Two mathematical models have been derived for the computation of the rollover limit of a standard farm tractor with pivoting front axle. The first model considers the tyres to be rigid bodies, while the second considers the vertical and lateral stiffness of the tyres.

The stiffness of the tyres plays a major role in the computation of the rollover limit of the vehicle, which can be overestimated up to $15 \%$ if tyre stiffness is neglected. The standard farm tractor presents a critical behaviour when one wheel is lifted. Depending on the conditions, the body can roll with respect to the front axle and a sudden rollover of the vehicle can happen. The lifting of one of the wheels has to be considered as the limit state for the rollover of the vehicle, being extremely unsafe the situation in which one wheel loses contact with the ground being extremely unsafe.

In the last part of the paper, a farm tractor equipped with a suspended front axle is considered. A mathematical model has been developed for the estimation of the rollover limit of this vehicle. The farm tractor equipped with a front axle suspension has shown a higher or at least an equal limit angle with respect to the standard farm tractor. The highest level of increment on the limit angles are in the most dangerous situations, where the lowest values of rollover angles are computed. The minimum rollover angle is incremented up to $20 \%$.

The front axle suspension can significantly improve the safety of the farm tractor when carrying a non-symmetric implement. In the case of the front axle suspension considered in the paper, an increment of more than $70 \%$ has been found on the minimum rollover angle. Finally, since in the configuration with front axle suspension the body does not have any free roll rotation with respect to the front axle, this configuration does not show any sudden change in its behaviour when one wheel is lifted.

\section{References}

Abubakar, M.S. Ahmad, D. and Akande, F.B. (2010) 'A review of farm tractor overturning accidents and safety', Pertanika Journal of Sciences \& Technology, Vol. 18, No. 2, pp.377-385.

Bastow, D. (1993) Car Suspension and Handling, Pentech Press, London.

Bunn, T.L., Slavova, S. and Hall, L. (2008) 'Narrative text analysis of Kentucky tractor fatality reports', Accident Analysis and Prevention, Vol. 40, pp.419-425. 
Day, L., Rechnitzer, G. and Lough, J. (2004) 'An Australian experience with tractor rollover protective structure rebate programs process, impact and outcome evaluation', Accident Analysis and Prevention, Vol. 36, pp.861-867.

Dixon, J.C. (1996) Tyres, Suspension and Handling, Society of Automotive Engineers Inc., Warrendale, Pa, ISBN: 978-1560918318.

EC Directive 2003/37/CE (2003) Available at. http://eur-lex.europa.eu/

EC Directive 2006/26/CE (2006) Available at. http://eur-lex.europa.eu/

Etherton, J.R., Myers, J.R., Jensen, R.C., Russell, J.C. and Braddee, R.W. (1991) 'Agricultural machine-related deaths', American Journal of Public Health, Vol. 81, No. 6, pp.766-768.

Febo, P. and Pessina, D. (2001) 'The elect of tyre size on the non-continuous rolling test for narrow tractors', Journal of Agricultural Engineering Research, Vol. 78, No. 2, pp.147-152.

Gibson, H.G., Elliott K.C. and Persson, S.P.E. (1971) 'Side slope stability of articulated-frame logging tractors', Journal of Terramechanics, Vol. 8, No. 2, pp.65-79.

Gillespie, T.D. (1992) Fundamentals of Vehicle Dynamics, Society of Automotive Engineers, Warrendale-United States.

Guzzomi, A.L., Rondelli, V., Guarnieri, A., Molari, G. and Molari, P.G. (2009) 'Available energy during the rollover of narrow-track wheeled agricultural tractors', Biosystems Engineering, Vol. 104, pp.318-323.

Hac, A., Brown, T. and Martens, J. (2004) 'Detection of vehicle rollover', SAE Technical Paper, No. 2004-01-1757.

Hunter, A.G.M. (1993) ‘A review of research into machine stability on slopes’, Safety Science, Vol. 16, No. 3-4, pp.325-339.

Loringer, K.A. and Myers, J.R. (2008) 'Tracking the prevalence of rollover protective structures on U.S. farm tractors: 1993, 2001 and 2004', Journal of Safety Research, Vol. 39, No. 5, pp.509-517.

Mangado, J., Arana, J.I., Jarén, C., Arazuri, S. and Arnal, P. (2007) 'Design calculations on rollover protective structures for agricultural tractors', Biosystems Engineering, Vol. 96, No. 2, pp.181-191.

Mashadi, B. and Nasrolahi, H. (2009) 'Automatic control of a modified tractor to work on steep side slopes', Journal of Terramechanics, Vol. 46, No. 6, pp.299-311.

Myers, M.L. (2000) 'Prevention effectiveness of rollover protective structure', Journal of Agricultural Safety and Health, Vol. 6, pp.29-70.

Myers, M.L., Cole, H.P. and Westneat, S.C. (2009) 'Injury severity related to overturn characteristics of tractors', Journal of Safety Research, Vol. 40, No. 2, pp.165-170.

Reynolds, S.J. and Groves, W. (2000) 'Effectiveness of roll-over protective structures in reducing farm tractor fatalities', American Journal of Preventive Medicine, Vol. 18, No. 4, pp.63-69.

SAE International Standard J1194 (2009) 'Rollover Protective Structures (ROPS) for wheeled agricultural tractors', Society of Automotive Engineers Inc.

Silleli, H., Dayiog̈lu, M.A., Gültekin, A., Ekmekçi, K., Yildiz, M.A., Akay, E. and Saranli, G. (2007) 'Anchor mechanism to increase the operator clearance zone on narrow-track wheeled agricultural tractors: prototype and first tests', Biosystems Engineering, Vol. 97, No. 2, pp.153-161.

Silleli, H., Dayiog̈lu, M.A., Gültekin, A., Saranli, G., Yildiz, M.A., Akay, E. and Ekmekçi, K. (2008) 'Anchor mechanism to increase the operator clearance zone on narrow-track wheeled agricultural tractors: static and field upset test results', Biosystems Engineering, Vol. 99, No. 2, pp.196-204.

Springfeldt, B. (1996) 'Rollover of tractors — international experiences', Safety Science, Vol. 24, No. 2, pp.95-110.

Yisa, M.G., Terao, H., Noguchi, N. and Kubota, M. (1998) 'Stability criteria for tractor-implement operation on slopes original research article', Journal of Terramechanics, Vol. 35, No. 1, pp.1-19. 


\section{Nomenclature}

\begin{tabular}{ll}
\hline$\sigma$ & orientation of the vehicle on the slope \\
$\beta$ & slope angle \\
$A$ & horizontal distance between the centre of front axle and the centre of gravity \\
$B$ & horizontal distance between the centre of rear axle and the centre of gravity \\
$p=\mathrm{a}+\mathrm{b}$ & wheel base \\
$t_{f}$ & half of the front track (evaluated at the midplane of the wheel) \\
$t_{r}$ & half of the rear track (evaluated at the midplane of the wheel) \\
$h_{f}$ & height of the roll centre, front \\
$h_{r}$ & height of the roll centre, rear (for no rear suspension and rigid tyre, $\left.h_{r}=0\right)$ \\
$h_{G}$ & height of the centre of gravity \\
$h_{0}$ & height of the roll axis at the centre of gravity \\
$y_{g}$ & lateral displacement of the centre of gravity \\
$F_{i}$ & force in the absolute vertical direction acting on each tyre $(I=1,2,3,4.1:$ \\
$F_{i z}$ & front left, $2:$ front right, 3: rear left, $4:$ rear right) \\
$F_{i x}$ & projection of the tyre force on the local $z$ coordinate \\
$F_{i y}$ & projection of the tyre force on the local $x$ coordinate \\
$w_{f}$ & projection of the tyre force on the local $y$ coordinate \\
$w_{\mathrm{r}}$ & width of the front tyres \\
$k_{f}$ & width of the rear tyres \\
$k_{f L}$ & vertical stiffness of the front tyres \\
$k_{r}$ & lateral stiffness of the front tyres \\
$k_{r L}$ & vertical stiffness of the rear tyres \\
\hline
\end{tabular}

\section{Appendix: Front axle suspension}

The front axle suspension scheme is briefly described. In Figure A1, the scheme of the front double wishbone suspension is shown, while in Figure A2, the hydro-pneumatic circuit is reported. The two actuators are connected by a cross circuit, i.e. the upper chamber of one is connected to the lower chamber of the other. In this way, a very high roll stiffness can be achieved.

Given the vertical load acting on the front axle, the initial volume of the air tanks can be computed.

$$
P_{\text {stat }}=\frac{\left(F_{z 1}+F_{z 2}\right)}{2 A_{r}}, \quad V_{\text {stat }}=V_{\text {initial }}\left(\frac{P_{\text {initial }}}{P_{\text {stat }}}\right)^{\frac{1}{k}}
$$

where $P_{\text {stat }}$ and $V_{\text {stat }}$ are the equilibrium pressure and volume of the tanks, $P_{\text {initial }}$ and $V_{\text {initial }}$ are the initial pressure and volume of the tanks, $A_{r}$ is the area of the rod of the pistons and $k$ is the gas constant. Due to the displacements $\Delta 1_{1}$ and $\Delta 1_{\mathrm{r}}$ of the left and right pistons, the volume variations of the two tanks can be computed as 
Figure A1 Scheme of the front axle suspension (the coordinates refer to the suspension considered in the paper)

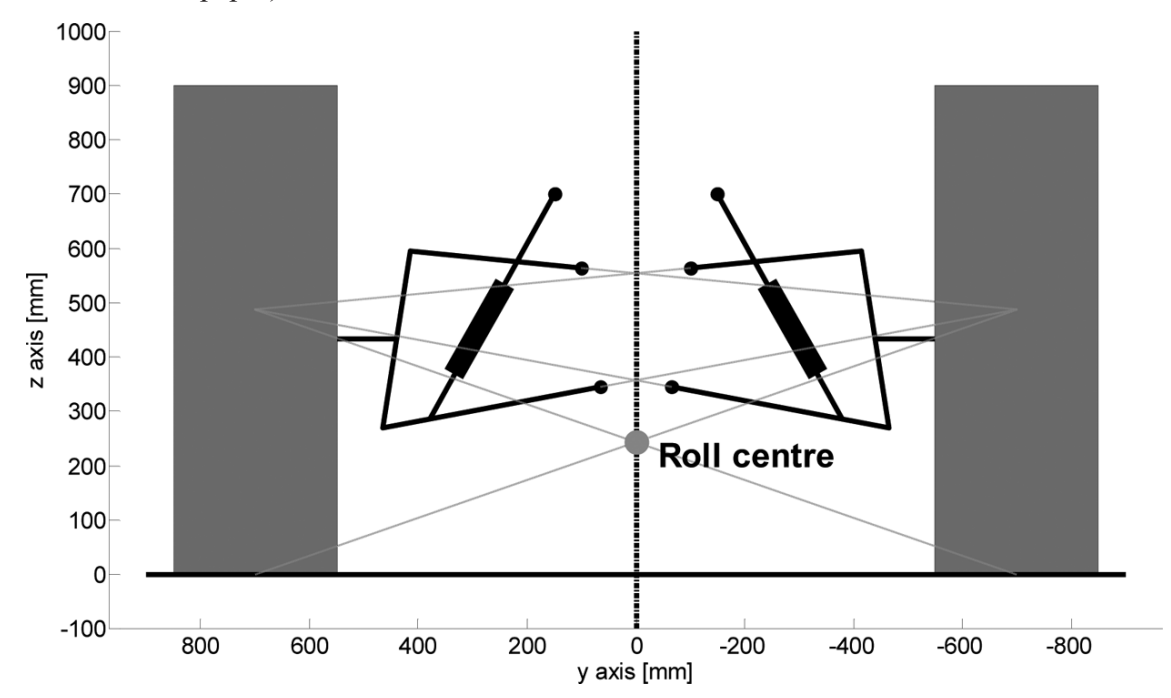

Figure A2 Hydro-pneumatic circuit

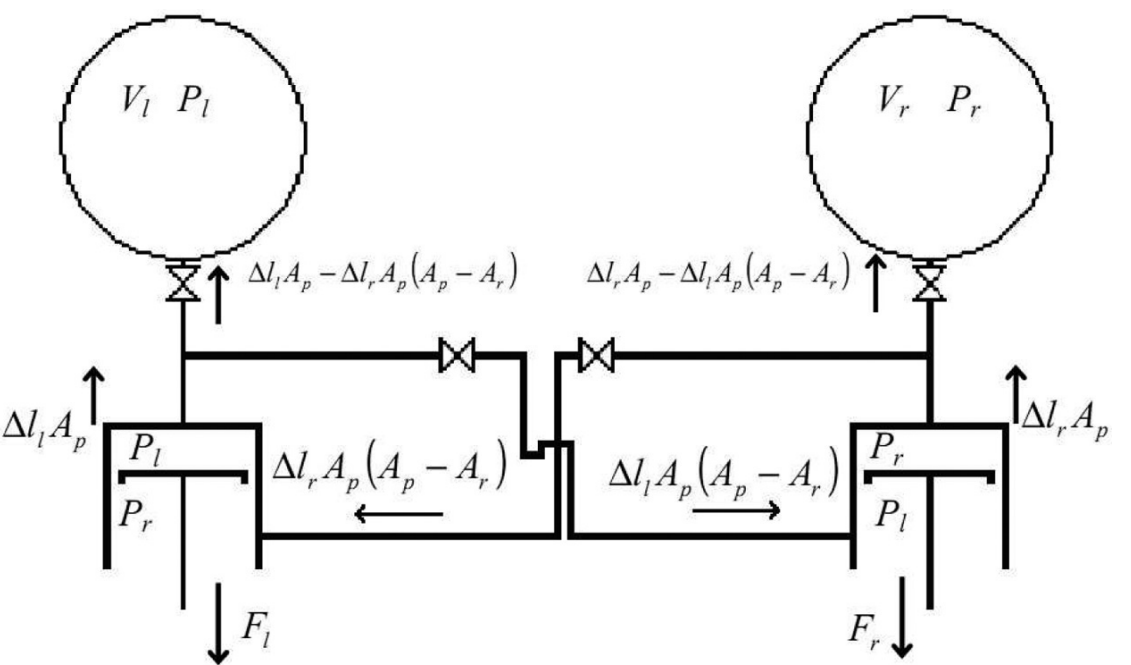

$$
V_{r}=V_{\text {stat }}-\left(A_{p} \Delta l_{r}-\left(A_{p}-A_{r}\right) \Delta l_{l}\right), \quad V_{l}=V_{\text {stat }}-\left(A_{p} \Delta l_{l}-\left(A_{p}-A_{r}\right) \Delta l_{r}\right)
$$

where $A_{p}$ is the area of the two pistons. The tank pressures are

$$
P_{r}=P_{\text {initial }}\left(\frac{V_{\text {initial }}}{V_{r}}\right)^{k}, \quad P_{l}=P_{\text {initial }}\left(\frac{V_{\text {initial }}}{V_{l}}\right)^{k} .
$$

Finally the forces acting on the two actuators are computed as 


$$
F_{r}=P_{r} A_{p}-P_{l} \cdot\left(A_{p}-A_{r}\right), \quad F_{l}=P_{l} A_{p}-P_{r} \cdot\left(A_{p}-A_{r}\right)
$$

From the relationship between the displacements and the forces on the actuators and the geometry of the suspension, the roll stiffness of the suspension can be computed. By considering also the roll stiffness due to the tyres, the global roll stiffness of the suspension is derived and shown in Figure 14. The main parameters of the suspension and of the hydropneumatic circuit are reported in Table A1.

Table Al Front axle suspension data

\begin{tabular}{ll}
\hline Front track $\left(t_{f}\right)$ & $0.7 \mathrm{~m}$ \\
Front axle roll centre height $\left(h_{f}\right)$ & $0.244 \mathrm{~m}$ \\
Initial tanks volume $\left(V_{\text {initial }}\right)$ & $0.5^{*} 10^{-3} \mathrm{~m}^{3}$ \\
Initial tanks pressure $\left(P_{\text {initial }}\right)$ & $5^{*} 10^{5} \mathrm{~Pa}$ \\
Piston area $\left(A_{p}\right)$ & $3.85^{*} 10^{-3} \mathrm{~m}^{*}$ \\
Rod area $\left(A_{r}\right)$ & $2.83^{*} 10^{-3} \mathrm{~m}^{*}$ \\
Gas constant $(k)$ & 1.4 \\
\hline
\end{tabular}

